\title{
VARIEDADES DE SOJA DIFEREM NA VELOCIDADE E CAPACIDADE DE ABSORVER ÁGUA
}

\section{SOYBEAN VARIETIES DIFFER IN THE VELOCITY AND CAPACITY OF WATER ABSORPTION}

\author{
José Antonio COSTA ${ }^{1}$ \\ João Leonardo Fernandes PIRES ${ }^{2}$ \\ André Luis THOMAS ${ }^{3}$ \\ Marilac ALBERTON ${ }^{4}$
}

\begin{abstract}
RESUMO
As sementes iniciam a retomada dos processos metabólicos a partir da embebição. Esta supre a necessidade de água para reduzir a resistência mecânica do tegumento, hidratar o embrião e cotilédones, induzindo o embrião a ativar enzimas que aceleram o processo de quebra de materiais de reserva usados para dar início à germinação da semente. Este experimento, realizado na Faculdade de Agronomia da Universidade Federal do Rio Grande do Sul, Porto Alegre, RS, no ano de 1993, objetivou avaliar o comportamento de cultivares de soja quanto à capacidade máxima e velocidade de absorção de água, em intervalos de hora, até oito horas consecutivas, quando em embebição total em água. Foram utilizadas sementes de 17 cultivares com tamanho uniformizado para diâmetro maior que $6,3 \mathrm{~mm}$ e ausência de rachaduras no tegumento quando observadas através de lupa. A cultivar 'RS 6 Guassupi' apresentou a maior velocidade e capacidade total de absorção de água. 'FT Abyara'e 'Bragg' apresentaram a menor velocidade e menor capacidade total de absorção nas primeiras horas de embebição, mas nas ultimas horas foi a 'RS 7 Jacuí que apresentou a menor capacidade de absorção. Este estudo permitiu concluir que existem diferenças na velocidade e na capacidade total de absorver água entre as cultivares testadas, devido a alguma característica distinta entre elas, que não foi investigada neste trabalho e que torna suas sementes mais ou menos permeáveis a água.

Palavras-chave: germinação, hidratação de sementes, capacidade de embebição velocidade de
\end{abstract} embebição.

\begin{abstract}
The seeds resume the metabolic process by imbibition, which supplies the necessity of water and promote the beginning of germination. The present study, performed at the Faculdade de Agronomia of Universidade Federal do Rio Grande do Sul, Porto Alegre, RS, in the 1993 year, was undertaken to evaluate the behavior of soybean cultivars in relation to maximum capacity and velocity of water absorption, measured in hourly intervals, for eight consecutive hours, in total imbibition in water. Seeds of 17 cultivars with diameter larger than $6.3 \mathrm{~mm}$ and with absence of cracks when observed with binocular in the seed coat were utilized The cultivar 'RS 6 Guassupi' showed the highest velocity and capacity of water absorption. 'FT Abyara' and 'Bragg' showed the smallest velocity and capacity of water absorption in the first hours of imbibition, but in the last hours 'RS 7 Jacuí' was the one which presented the smallest water absorption capacity. The conclusion from this study is that the cultivars tested have some distinct caracteristic that allowed for the diferences in the water imbibition velocity and total capacity of water absorption that was not detected in this research.
\end{abstract}

Key-words: germination, seed hydration, imbibition capacity, imbibition velocity.

\footnotetext{
${ }^{1}$ Eng. Agr., Ph.D. - Prof. Titular do Departamento de Plantas de Lavoura, Faculdade de Agronomia/UFRGS, Caixa Postal 776, 90001-970, Porto Alegre, RS. Bolsista do CNPq. E-mail: plantas@vortex.ufrgs.br Autor para correspondência.

${ }^{2}$ Eng. Agr., M.Sc. - Aluno de pós-graduação em Agronomia - Fitotecnia, Faculdade de Agronomia/UFRGS. Bolsista do CNPq. E-mail: piresj|@vortex.ufrgs.br

${ }^{3}$ Eng. Agr., M.Sc. - Prof. Assistente do Departamento de Plantas de Lavoura, Faculdade de Agronomia/UFRGS.

${ }^{4}$ Eng. Agr., M.Sc.
} 
COSTA, J.A. et al. Variedades de soja diferem na velocidade...

\section{INTRODUÇÃO}

Uma das etapas fundamentais para a obtenção de rendimentos elevados em soja é o estabelecimento de um estande adequado de plantas (com população e arranjo de acordo com as recomendações da pesquisa). No entanto, fatores como uso de sementes de baixo vigor, deficiência hídrica e preparo do solo inadequado, podem estar envolvidos na não obtenção do estande desejado (13). Estes fatores, por estarem relacionados com a qualidade da semente, disponibilidade de umidade e características inerentes ao solo, tem influência nos processos iniciais de determinação do estande, que são a germinação e emergência da cultura.

A absorção de água pelas sementes dá início ao processo de germinação que, segundo Bewley e Black (1) e Labouriau (9), é trifásica em condições ótimas. A primeira fase, ou embebição, é um processo físico (não associado com a viabilidade da semente) que é determinado por três fatores principais: composição (química e estrutural) da semente, características do tecido que reveste a semente e a disponibilidade de água no estado líquido ou gasoso (relacionados com o microambiente do solo) (17). A embebição é consequência das forças matriciais, e a quantidade de água absorvida em função do tempo origina uma curva sigmoidal $(1 ; 9)$.

$\mathrm{Na}$ segunda fase, a quantidade de água absorvida é proporcional ao tempo e está ligada ao metabolismo da semente em processo de germinação, sendo suprimida quando o metabolismo respiratório é suspenso. Esta fase da hidratação é sempre seguida de uma terceira de grande velocidade, fora do âmbito natural do processo de germinação, onde ocorre o alongamento da radícula $(1 ; 9)$. A quantidade de água absorvida na germinação varia com a espécie e com as condições a que a semente tenha sido submetida desde a maturação (9).

Já a velocidade com que a água é absorvida pela semente depende da espécie, permeabilidade do tegumento, disponibilidade de água, temperatura, pressão hidrostática, área de contato semente/água, forças intermoleculares, composição química e condições fisiológicas (14). Uma embebição prolongada, principalmente sob baixos potenciais hídricos, pode ter reflexos bastante grandes na velocidade, sincronia e porcentagem de germinação das sementes (2). A velocidade de embebição é afetada quando as condições de ambiente variam, mas a quantidade máxima de água absorvida nessa etapa não se altera, pois esse máximo é uma propriedade dos colóides hidrofílicos da semente, condicionada pela maturação e/ou pelo armazenamento (9). Em soja, as proteínas são as principais responsáveis pelo fenômeno da embebição, devido a sua natureza hidrofílica (15).

Muitos fatores relacionados a planta mãe podem afetar as características das sementes com reflexos na sua embebição. Um deles é a suplementação hídrica durante o período de enchimento de grãos.
Esta prática de manejo pode influenciar a característica de impermeabilidade do tegumento e a germinação de sementes não escarificadas que possuam esta característica (7).

Vieira et al. (20) observaram aumento na percentagem de água absorvida nas primeiras horas de embebição de sementes de soja, à medida que ocorreu o retardamento da colheita, e sugeriram que este resultado poderia ser atribuído à menor resistência oferecida pelo tegumento, dado o aumento da permeabilidade com a elevação do grau de deterioração da semente.

Existem indicativos que diferenças na condutividade elétrica entre cultivares de soja podem estar relacionadas a variação no conteúdo de lignina no tegumento da semente. Este conteúdo está correlacionado com a resistência da semente a danos mecânicos e também indica que a alta lignificação do tegumento torna difícil o processo de embebição e o proceso de perda de substâncias que podem ser lixiviadas da semente (4).

Portanto, o tegumento tem função importante na germinação, pois é um fator regulador da embebição da semente $(5 ; 10)$. Segundo Calero et al. (5), a absorção de água pela semente de soja é controlada pelo menos por dois fatores: 1) forma e tamanho dos poros do tegumento e 2) quantidade de material ceroso embebido na epiderme. Quando não há poros e o material ceroso está embebido na epiderme, a embebição de água pela semente é vagarosa. Da mesma forma, Kulik e Yaklich (8), já se conhece o efeito do tegumento na redução de infecção de sementes por Phomopsis phaseoli, onde verificou-se que a resistência de algumas cultivares a infecção pelo fungo é devida a características físicas relacionadas a impermeabilidade do tegumento.

Trabalhos com trigo, tem demonstrado que, com o uso de modelos matemáticos e propriedades do solo facilmente mensuráveis é possível predizer a embebição de sementes em diversas condições de solo (17). Isto poderia ser feito também em soja.

O presente trabalho foi conduzido com o objetivo de determinar a capacidade máxima e a velocidade de absorção de água por sementes de 17 cultivares de soja.

\section{MATERIAL E MÉTODOS}

Foram utilizadas sementes das cultivares ' $F T$ Abyara', 'Bragg', 'BR 4', 'CEP 12 Cambará', 'CEP 16 Timbó', 'CEP 20 Guajuvira', 'CEP 26 Umbu', 'Cobb', 'EMBRAPA 19', 'IAS 4', 'IAS 5', 'IPAGRO 21', 'Ivorá', 'RS 5 Esmeralda', 'RS 6 Guassupi', 'RS 7 Jacuí' e 'RS 9 Itaúba', limpas e classificadas.

As sementes foram selecionadas pelo tamanho, por meio de peneira de furos quadrados com 6,3 $\mathrm{mm}$ de lado, sendo utilizadas as que ficaram retidas nesta peneira. Selecionaram-se as sementes também pela integridade do tegumento com auxílio de lupa. 
As sementes com rachaduras no tegumento foram descartadas.

Foram feitas as seguintes determinações:

\section{Peso seco e grau de umidade das sementes}

Para estas determinações foram utilizadas três repetições de 50 sementes, pesadas antes e após permanecerem em estufa a $65{ }^{\circ} \mathrm{C}$ até atingirem peso constante, o que ocorreu após 48 horas. O peso seco constitui o peso final, após a secagem. O grau de umidade foi determinado pela fórmula:

$$
U(\%)=\frac{M I-M F}{M I} \times 100
$$

onde:

$U(\%)=$ grau de umidade das sementes;

$\mathrm{MI}=$ massa inicial das sementes da amostra;

MF = massa final da amostra seca.

\section{Embebição em água}

Para a embebição em água foram utilizadas quatro repetições de 50 sementes selecionadas, por cultivar.

A metodologia aplicada foi descrita por VIEIRA et al. (20), com modificações no número de sementes por amostra, de 100 para 50 sementes. As amostras, após determinada a massa inicial de cada uma, foram colocadas em copos contendo água destilada em quantidade suficiente para cobrí-las, sendo deixadas em embebição na temperatura de $25 \pm 2{ }^{\circ} \mathrm{C}$. No final de uma hora de embebição, as sementes de cada amostra eram retiradas dos copos com auxílio de uma peneira e enxugadas pela passagem sucessiva em bandejas com papel mata-borrão no fundo. As sementes sem brilho, pela ausência da película de umidade externa ao tegumento, foram consideradas enxutas. Depois as sementes foram pesadas e colocadas novamente em copos com água destilada. O processo descrito acima foi repetido desde duas até oito horas de embebição, em intervalo de uma hora, quando as sementes atingiram a capacidade máxima de absorção, de acordo com testes preliminares.

\section{Grau de umidade inicial}

A partir da determinação do grau de umidade das sementes feita anteriormente, foi utilizada a fórmula:

$$
\text { GUI }(\%)=\frac{M I \times U}{100} \times 100
$$

onde:

GUI = grau de umidade inicial das sementes antes de submetê-las à embebição, em gramas de $\mathrm{H}_{2} \mathrm{O}$;

$\mathrm{MI}=$ massa inicial das sementes obtido antes da embebição, em gramas;

$U(\%)=$ grau de umidade das sementes da amostra.

4. Grau de umidade nos diferentes tempos de embebição

Com a massa obtida após os sucessivos intervalos de embebição, massa inicial das amostras e grau de umidade inicial, foi aplicada a fórmula:

$$
\mathrm{GU}=\mathrm{MF}-\mathrm{MI}+\mathrm{GUI}
$$

onde:

$\mathrm{GU}=$ grau de umidade atingido pelas sementes na hora $\mathrm{x}$, em gramas de $\mathrm{H}_{2} \mathrm{O}$;

MF = massa final das sementes obtido após $\mathrm{x}$ horas de embebição, em gramas;

$\mathrm{MI}=$ massa inicial das sementes antes de submetêlas à embebição, em gramas;

GUI = grau de umidade inicial das sementes antes de submetê-las à embebição, em gramas.

A partir desses cálculos, foi obtido o teor cumulativo de água absorvida em todos os intervalos testados, ou seja, a capacidade de absorção de água em cada período de tempo. Esse valor, expresso em gramas de $\mathrm{H}_{2} \mathrm{O}$, foi dividido pela diferença da MF e o GUI, que representa a massa seca das sementes. Desse modo submeteu-se a análise estatística os valores expressos pela razão das gramas de $\mathrm{H}_{2} \mathrm{O}$ absorvida na embebição e as gramas de sementes secas de cada amostra.

\section{RESULTADOS E DISCUSSÃO}

A velocidade de absorção de água mostrou diferenças entre cultivares, já na primeira hora de embebição. A cultivar 'RS 6 Guassupí' apresentou maior velocidade de absorção em todos os tempos testados. As cultivares 'FT Abyara' e 'Bragg', a menor velocidade de absorção na primeira hora de embebição. Porém, a partir da quinta hora, a menor velocidade de absorção foi evidenciada na 'RS 7 Jacuí' (Tabela 1).

A resposta das cultivares quanto à capacidade de absorção de água em função do tempo de embebição foi quadrática, indicando que a quantidade de água absorvida foi se tornando menor, estabilizando nas últimas horas. Na Figura 1, como ilustração, estão representadas três das 17 cultivares testadas, as quais demonstraram a maior, intermediária e menor capacidade de absorção de água. 
COSTA, J.A. et al. Variedades de soja diferem na velocidade...

TABELA 1 - Massa de 50 sementes secas de soja com diâmetro maior de 6,3 mm e a razão entre gramas de $\mathrm{H}_{2} \mathrm{O}$ absorvida na primeira, quinta e oitava horas de embebição das sementes e o peso das sementes secas. UFRGS/FA, Porto Alegre, 1993.

\begin{tabular}{|c|c|c|c|c|}
\hline \multirow[t]{2}{*}{ Cultivares } & \multirow{2}{*}{$\begin{array}{c}\text { Massa das } \\
\text { Sementes } \\
\text { secas }\end{array}$} & \multicolumn{3}{|c|}{$\mathrm{g} \mathrm{H}_{2} \mathrm{O}$ absorvida/g de sementes secas } \\
\hline & & $1^{\circ}$ hora & $5^{\circ}$ hora & $8^{\circ}$ hora \\
\hline FT Abyara & 8,8 cdefgh* & $0,49 \mathrm{~d}$ & $1,07 \mathrm{~cd}$ & 1,29 cdefg \\
\hline Bragg & 9,0 bcdef & $0,48 d$ & $1,07 \mathrm{~cd}$ & $1,30 \mathrm{cdef}$ \\
\hline BR 4 & 8,8 defgh & $0,56 \mathrm{abcd}$ & $1,12 \mathrm{bcd}$ & 1,35 bcde \\
\hline CEP 12 Cambará & $9,7 a$ & $0,50 \mathrm{~cd}$ & $1,09 \mathrm{bcd}$ & 1,28 defg \\
\hline CEP 16 Timbó & $9,5 \mathrm{abc}$ & $0,53 \mathrm{abcd}$ & $1,11 \mathrm{bcd}$ & 1,33 bcdef \\
\hline CEP 20 Guajuvira & $8,3 \mathrm{gh}$ & $0,52 \mathrm{bcd}$ & 1,09 bcd & 1,32 bcdef \\
\hline CEP 26 Umbu & $9,8 \mathrm{a}$ & $0,54 \mathrm{abcd}$ & $1,15 a b$ & 1,34 bcde \\
\hline Cobb & $9,6 a b$ & $0,56 \mathrm{abcd}$ & $1,10 \mathrm{bcd}$ & $1,27 \mathrm{efg}$ \\
\hline EMBRAPA 19 & 8,6 efgh & $0,52 \mathrm{bcd}$ & $1,09 \mathrm{bcd}$ & $1,26 \mathrm{fg}$ \\
\hline IAS 4 & 9,3 abcde & $0,53 \mathrm{abcd}$ & $1,09 \mathrm{bcd}$ & 1,30 cdef \\
\hline IAS 5 & 9,4 abcd & $0,58 a b c$ & $1,10 \mathrm{bcd}$ & 1,29 cdefg \\
\hline IPAGRO 21 & $7,5 \mathrm{i}$ & $0,50 \mathrm{~cd}$ & $1,08 \mathrm{~cd}$ & 1,33 bcde \\
\hline Ivorá & $8,3 \mathrm{~h}$ & $0,54 \mathrm{abcd}$ & $1,13 \mathrm{bcd}$ & 1,31 bcdef \\
\hline RS 5 Esmeralda & $8,2 \mathrm{~h}$ & $0,59 a b$ & $1,16 a b$ & $1,35 \mathrm{bc}$ \\
\hline RS 6 Guassupí & 9,7 a & $0,60 \mathrm{a}$ & $1,23 \mathrm{a}$ & $1,43 a$ \\
\hline RS 7 Jacuí & $8,3 \mathrm{fgh}$ & $0,53 \mathrm{abcd}$ & $1,06 \mathrm{~d}$ & $1,22 \mathrm{~g}$ \\
\hline RS 9 Itaúba & 8,9 bcdef & $0,51 \mathrm{bcd}$ & $1,13 \mathrm{bc}$ & $1,38 a b$ \\
\hline
\end{tabular}

*Médias seguidas de mesma letra na coluna não diferem significativamente pelo teste de TUKEY a $5 \%$ de probabilidade.

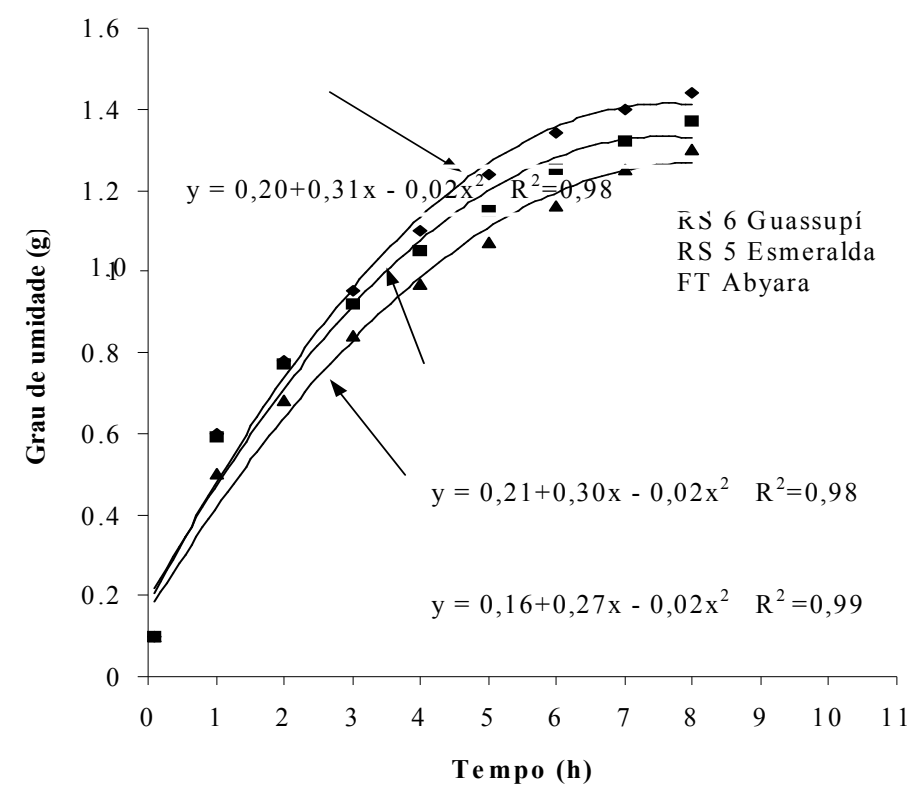

FIGURA 1 - Água absorvida por 50 sementes de soja, com diâmetro maior de 6,3 mm, das cultivares RS 6 Guassupí, RS 5 Esmeralda e FT Abyara, em função do tempo de embebição. DPL/FA/UFRGS, Porto Alegre, RS, 1993. 
A capacidade máxima de absorção de água, que foi atingida na oitava hora de embebição, correlacionou-se positivamente com a massa das sementes secas (Figura 2). Mas, quando foi conside- rado a capacidade máxima de absorção por grama de massa de semente seca, a correlação não foi observada $\left(r^{2}=0,14\right)$.

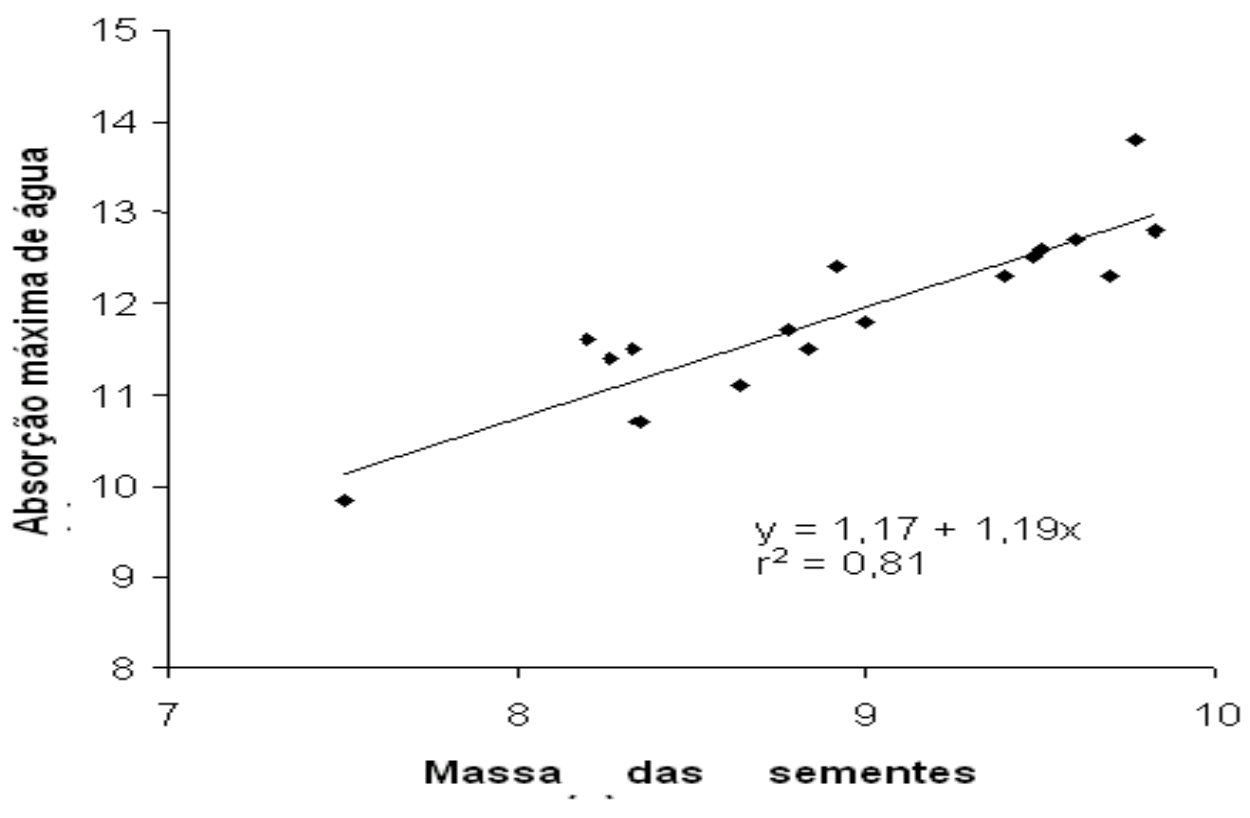

FIGURA 2 - Capacidade máxima de absorção de água após oito horas de embebição, em função da massa de 50 sementes secas de soja, com diâmetro maior de 6,3 mm. DPL/FA/UFRGS, Porto Alegre, RS, 1993.

A velocidade de absorção de água, medida em $\mathrm{g} \mathrm{H}_{2} \mathrm{O}$ absorvida / $\mathrm{g}$ de matéria seca, não depende da massa da semente seca, indicando que há algum fator que altera o comportamento de cultivares como a 'RS 6 Guassupí' e 'CEP 12 Cambará', com a mesma quantidade de matéria seca porém velocidade de absorção diferentes. Esse fator, provavelmente, seja a permeabilidade do tegumento, pois Calero et al. (5) e Mcdonald et al. (10) consideraram o tegumento como um fator regulador da embebição da semente. Com base nessas informações, se pode inferir que a 'CEP 12 Cambará' possuiria o tegumento menos permeável à água do que a 'RS 6 Guassupí'. A medida direta da espessura e a composição do tegumento, entretanto, não foram realizadas neste trabalho.

Cultivares de soja com absorção lenta de água, de acordo com Calero et al. (5), podem possuir tegumentos com poros alongados e material ceroso embebido na epiderme, fato que torna o processo de embebição de água vagaroso. Além disso, conforme Tavares et al. (18), tegumentos escuros também atrasam o processo de embebição. Tegumentos com alto teor de lignina também podem influenciar a embebição. Sugere- se, para trabalhos futuros, a realização de estudo detalhado do tegumento de cultivares de soja, a fim de identificar que característica confere maior ou menor permeabilidade ao tegumento. Também a impermeabilidade total ou parcial da soja à penetração de água é uma característica que pode ser usada para produzir genótipos de soja com maior tolerância às adversidades meteorológicas, presentes após a maturidade fisiológica da semente (19). Santos et al. (16) verificaram, em condições de estresse hídrico, que a germinação é diretamente proporcional ao vigor da semente de soja. Sob maiores tensões, há uma redução da velocidade de embebição das sementes podendose evitar danos ao embrião em sementes de baixo vigor. Em sementes de alto vigor, o estresse hídrico quase não afeta a germinação até um potencial de -1,2 MPa, e com baixo vigor, não chega a inibir a germinação (12). Já para Braccini et al. (3), utilizando polietilenoglicol (PEG) para simular o efeito do déficit hídrico em diferentes cultivares, evidenciaram que algumas cultivares com melhor qualidade de sementes apresentaram desempenho satisfatório até o nível de potencial osmótico de $0,1 \mathrm{MPa}$, enquanto que outra cultivar, de pior qua- 
COSTA, J.A. et al. Variedades de soja diferem na velocidade...

lidade fisiológica, apresentou desempenho satisfatório até o nível de $-0,05 \mathrm{MPa}$, sendo que no nível de potencial osmótico de $-0,6 \mathrm{MPa}$, a germinação e o vigor das sementes foi praticamente insignificante.

As diferenças na quantidade total de água absorvida pelas sementes são devidas às alterações no tamanho dos cotilédones, conforme verificado por Mcdonald et al. (11), os quais são os grandes responsáveis pelo tamanho das sementes (6).

\section{CONCLUSÕES}

1. Existe diferença na velocidade de absorção de água pelas cultivares de soja.

2. Há alguma característica distinta entre as cultivares que torna suas sementes mais ou menos permeáveis a água.

3. As diferenças observadas na velocidade de absorção, no entanto, em termos práticos, não são bastante pronunciadas para gerar diferenças na germinação da soja no campo.

\section{REFERÊNCIAS BIBLIOGRÁFICAS}

1 BEWLEY, J.D.; BLACK, M. Seeds: physiology of development and germination. New York: Plenum Press, 1985. 367p.

2 BRACCINI, A. de L.; REIS, M.S.; SEDIYAMA, C.S.; SCAPIM, C.A.; BRACCINI, M. do C.L. Avaliação da qualidade fisiológica de sementes de soja, após o processo de hidratação-desidratação e envelhecimento acelerado. Pesquisa Agropecuária Brasileira, Brasília, v.34, n.6, p.1053-1066, 1999.

3 BRACCINI, A. de L. e; REIS, M.S.; SEDIYAMA, C.S.; SEDIYAMA, T.; ROCHA, V.S. Influência do potencial hídrico induzido por polietilenoglicol na qualidade fisiológica de sementes de soja. Pesquisa Agropecuária Brasileira, Brasília, v.33, n.9, p.1451-1459, 1998.

4 CABALLERO AVAREZ, P.J. Relação entre o conteúdo de lignina no tegumento da semente de soja e sua relação ao dano mecânico. Londrina: UEL/Embrapa/IAPAR, 1994. 43p. Tese de Mestrado.

5 CALERO, E.; WEST, S.H.; HINSON, K. Water absorption of soybean seeds and associated causal factors. Crop Science, Madison, v.21, n.6, p.926-933, 1981.

6 COSTA, J.A,.; WOLLMANN, L.M. Contribuição relativa do tegumento, cotilédones e embrião na matéria seca total da semente de soja. Pesquisa Agropecuária Brasileira, Brasília, v.24, n.4, p.451-453, 1989.

7 HEATHERLY, L.G.; KENTY, M.M. Irrigation during seedfill and germinability of soybean with impermeable seed coat character. Crop Science, v.35, n.1, p.205-208, 1995.

8 KULIK, M.M.; YAKLICH, R.W. Soybean seed coat: relationship to weathering resistance and infection by the fungus Phomopsis phaseoli. Crop Science, Madison, v.31, n.1, p.108-113, 1991.

9 LABOURIAU, L.G. A germinação das sementes. Washington: OEA, 1983. 174p.

10 McDONALD, M.B.; VERTUCCI, C.W.; ROOS, E.E. Seed coat regulation of soybean seed imbibition. Crop Science, Madison, v.28, n.6, p.987-992, 1988, a.

11 McDONALD, M.B.; VERTUCCI, C.W.; ROOS, E.E. Soybean seed imbibition: water absorption by seed parts. Crop Science, Madison, v.28, n.6, p.993-997, 1988, b.

12 NÓBREGA, L.H.P.; RODRIGUES, T.J.D.; MALHEIROS, E.B.; NÓBREGA, J.C.M. de Deficiência hídrica na germinação de sementes de soja. Revista Brasileira de Sementes, Brasília, v.20, n.1, p.126-133, 1998.

13 PÔNZIO, J.B.; SEDIYAMA, T.; ROCHA, V.S.; SEDIYAMA, C.S. Influência da correção do número de sementes visando ao estabelecimento do estande e de outras características agronômicas da soja. Revista Brasileira de Sementes, Brasília, v.20, n.2, p.327-333, 1998.

14 POPINIGIS, F. Fisiologia da semente. Brasília: AGIPLAN, 1977. 289p.

15 ROCHA, V.S.;OLIVEIRA, A.B.; SEDIYAMA, T.; GOMES, J.L.L.; SEDIYAMA, C.S.;PEREIRA, M.G. A qualidade da semente de soja. Viçosa: UFV, 1990. 76p.

16 SANTOS, V.L.M.; CALIL, A.C.; RUIZ, H.A.; ALVARENGA, E.M.; SANTOS, C.M. Efeito do estresse salino e hídrico na germinação e vigor das sementes de soja. Revista Brasileira de Sementes, Brasília, v.14, n.2, p.189-194, 1992.

17 STUDDERT, G.A.; WILHELM, W.W.; POWER, J.F. Imbibition response of winter wheat to water-filled pore space. Agronomy Journal, Madison, v.86, n.6, p.995-1000, 1994.

18 TAVARES, D.Q.; UMINO, C.Y.; DIAS, G.M.; MIRANDA, M.A.C. Compostos fenólicos no tegumento de sementes de linhagens de soja permeável e impermeável. Revista Brasileira de Botânica, São Paulo, v.9, p.167-171, 1986.

19 VIEIRA, R.D.; MINOHARA, L.; PANOBIANCO, M.; BERGAMASCHI, M.C.; MAURO, A.O. Comportamento de cultivares de soja quanto a qualidade fisiológica de sementes. Pesquisa Agropecuária Brasileira, Brasília, v.33, n.2, 1998.

20 VIEIRA, R.D.; SEDIYAMA, T.; SILVA, R.F. da; SEDIYAMA, C.S.; THIÉBAUT, J.T.L. Efeito do retardamento.da colheita, sobre a qualidade de sementes de soja cv 'UFV 2'. Revista Brasileira de Sementes, Brasília, v.4, n.2, p.9-22, 1982. 